\title{
Exposure to toluene increases the urinary excretion of D-glucaric acid*
}

\author{
A Moretto, M Lotti
}

\begin{abstract}
Workers at a printing plant exposed to low concentrations of toluene $\left(43-401 \mathrm{mg} / \mathrm{m}^{3}\right.$, median $155 \mathrm{mg} / \mathrm{m}^{3}$ ) had increased urinary $D$ glucaric acid (3.55-5.12 $\mathrm{mmol} / \mathrm{mol}$ creatinine) excretion at the end of the shift compared with controls $(2.45-3.35 \mathrm{mmol} / \mathrm{mol}$ creatinine). No increase was found after the summer holiday (1.92-2.89 $\mathrm{mmol} / \mathrm{mol}$ creatinine) but excretion had increased two weeks later (4.05$5.55 \mathrm{mmol} / \mathrm{mol}$ creatinine). These changes in the excretion of D-glucaric acid were not correlated to levels of exposure, to changes of urinary hippuric acid and o-cresol half lives (three to eight hours), nor to o-cresol/hippuric acid concentration ratios when measured at the end of daily exposure. Since a significant intra and interindividual variability of urinary D-glucaric acid was found in all groups, urinary D-glucaric acid excretion is suitable to monitor group but not individual exposure.
\end{abstract}

Toluene is used in various industrial processes as a chemical intermediate and solvent. ${ }^{1}$ The target organ for toluene toxicity in man and in experimental animals is the central nervous system (extensive review ${ }^{2}$ ). In experimental animals, however, exposure to toluene also causes an increase of cytochrome P-450 and of some microsomal enzymes in the liver and other organs..$^{3-6}$ These biochemical effects are associated with an increase in mitochondria and the proliferation of smooth endoplasmic reticulum in hepatocytes suggesting liver microsomal enzyme induction. ${ }^{\text {? }}$

Changes in microsomal enzyme activity caused by occupational exposures are usually not accompanied by clinical signs of toxicity but they are regarded as a sensitive index of biological changes. The assessment

«Part of these results were communicated at the International Conference on Organic Solvent Toxicity, 15-17 October 1984, Stockholm, Sweden.

Istituto di Medicina del Lavoro dell'Università di Padova, I-35127 Padua, Italy

A Moretto, $M$ Lotti of liver microsomal enzyme function by means of non-invasive tests, such as saliva antypyrine half life and D-glucaric acid and 6- $\beta$-hydroxycortisol excretion in urine, was therefore proposed for the biological monitoring of occupational exposures to several chemicals. $^{8}$

D-glucaric acid is the end product of the glucuronic acid pathway involving several enzymes present in the cytosol but not in the microsomes. Urinary D-glucaric acid (UDGA) excretion in man was shown to increase after treatment with certain drugs such as phenobarbitone and aminopyrine. ${ }^{9}$ In some species but not in man and guinea pigs Dglucaric acid is converted into ascorbic acid and no UDGA is detectable. In guinea pigs treated with phenobarbitone high correlation was found between liver P-450 content and daily UDGA excretion. When animals were pretreated with an inhibitor of protein synthesis before treatment with phenobarbitone, UDGA excretion decreased with decrease in the level of liver $\mathrm{P}-450 .^{10}$ This observation suggested that measurement of UDGA would provide a quantitative although indirect estimate of hepatic enzyme activity. The rate limiting step of this pathway is unknown even though the enzymes involved in Dglucaric acid formation are increased during enzyme induction. ${ }^{11}$

We report here on excretions of UDGA and toluene metabolite in workers occupationally exposed to low concentrations of toluene in a rotogravure printing plant.

\section{Materials and methods} SUBJECTS

We studied workers in a printing plant where the ink used in the rotogravure was diluted with pure toluene. Toluene was also used to clean the printing machine. The workers were subdivided as follows.

Group $A(n=7)$ Workers studied for eight days (Monday to Monday) before the summer holidays (four weeks). They were also studied for one day immediately and 50 days after the end of the summer holidays.

Group $B(n=7)$ Workers studied for 15 days immediately after returning from summer holidays and for one day 36 days thereafter.

Group $C(n=9)$ Workers studied for one day, 
one and 28 days after a short holiday ( 10 days). This group was formed of individuals from the two previous groups.

Control workers $(n=16)$ from the same plant but not exposed to toluene were matched with the exposed workers for age, smoking, and food habits and monitored daily for UDGA and hippuric acid excretion from Monday to Friday for one week only to be compared with group $A$. In the remaining experiments each group acted as its own control.

\section{ENVIRONMENTAL MONITORING}

Environmental exposure to toluene of each worker was assessed as the TWA for the first and second half of the shift on the same days when urine was collected for UDGA, hippuric acid, and o-cresol determinations, except after summer holidays for group $A$ and the 51st day after the summer holiday for group B. Air samples were obtained with activated charcoal personal dosimeters and toluene concentration was measured according to the NIOSH method. ${ }^{12}$

\section{URINE COLLECTION AND ANALYSIS}

In groups A and B urine samples were collected before and after the workshift and in group $C$ urine samples were collected for 17 hours after the workshift. Samples were stored at $-20^{\circ} \mathrm{C}$ until analyses were performed. Urinary hippuric acid and o-cresol were measured by HPLC according to De Rosa et al. ${ }^{13} \mathrm{D}$-glucaric acid was measured according to Colombi et al. ${ }^{14}$ All values were then corrected for creatinine content.

\section{Results}

Exposure levels have been extensively reported elsewhere. ${ }^{1516}$ Environmental toluene (range of daily means: $87-301 \mathrm{mg} / \mathrm{m}^{3}$, median $155 \mathrm{mg} / \mathrm{m}^{3}$ ) never exceeded the TLV of $375 \mathrm{mg} / \mathrm{m}^{3}$ proposed by ACGIH for $1987^{17}$ except for a single day exposure for one worker. Urinary hippuric acid (range of daily means: $0.44-1.15 \mathrm{~mol} / \mathrm{mol}$ creatinine, median $0.97 \mathrm{~mol} / \mathrm{mol}$ of creatinine) and o-cresol (range of daily means: $205-531 \mu \mathrm{mol} / \mathrm{mol}$ creatinine, median $407 \mu \mathrm{mol} / \mathrm{mol}$ of creatinine) were correlated to the environmental concentration of the solvent. ${ }^{16}$ No significant differences were found in exposure between groups $\mathbf{A}$ and $\mathbf{B}$.

The table shows the values of postshift UDGA in group A workers measured for a week four weeks before summer holidays and in controls. UDGA in the exposed workers was significantly higher than in the non-exposed workers. Control values were comparable to those already reported. ${ }^{18}$ When measured immediately after the holidays, however, UDGA excretion in group A workers did not differ from that of the controls $(2.45 \pm 0.14 \mathrm{mmol} / \mathrm{mol}$ creatinine, mean $\pm S E M, n=7$ ). After 50 days exposure,
$U D G A$ excretion in toluene exposed (group A) and control subjects

\begin{tabular}{lll}
\hline & \multicolumn{2}{l}{$U D G A(\mathrm{mmol} / \mathrm{mol}$ creatinine) } \\
\cline { 2 - 3 } Day & $\begin{array}{l}\text { Exposed } \\
(n=7)\end{array}$ & $\begin{array}{l}\text { Controls } \\
(n=16)\end{array}$ \\
\hline Monday & $3.55 \pm 0.40$ & $2 \cdot 72 \pm 0.23$ \\
Tuesday & $4.44 \pm 0.50$ & $2.59 \pm 0.21$ \\
Wednesday & $3.97 \pm 0.35$ & $3.35 \pm 0.22$ \\
Thursday & $5.11 \pm 0.36$ & $3.05 \pm 0.18$ \\
Friday & $3.98 \pm 0.36$ & $2.45 \pm 0.16$ \\
Saturday & $5.12 \pm 0.99$ & - \\
Monday & $5.02 \pm 0.33$ & - \\
\hline
\end{tabular}

UDGA values of exposed workers are significantly higher than those of control subjects ( $p<0.001$ with analysis of variance for repeated measures). A significant day to day variation (Greenhose-Geisser probability < 0.002) of UDGA values was found in both groups. (Data are expressed as mean \pm SEM.)

UDGA excretion was again high $(3.79 \pm 0.31$ $\mathrm{mmol} / \mathrm{mol}$ creatinine, mean $\pm \mathrm{SEM}, \mathrm{n}=7$ ).

The values of UDGA in group $B$ are reported in the figure. Immediately after the summer holidays, UDGA excretion was comparable to that of nonexposed workers; the values then increased, reaching, in about two weeks, a plateau level comparable with that of group A. No correlation was found in groups $A$ and $B$ between individual postshift UDGA and urinary hippuric acid or o-cresol excretion or environmental exposure as assessed on the same day.

To see whether increased UDGA was associated with a different pattern or time course, or both, of metabolite excretion, urinary hippuric acid and ocresol were monitored for $\mathbf{1 7}$ hours after the end of the workshift in group $\mathrm{C}$ workers on two occasions. Immediately after a short holiday UDGA excretion was similar to that of controls $(2.33 \pm 0.12 \mathrm{mmol} /$ mol creatinine) and increased by about $25 \%$ four weeks later. The time courses of excretion of hippuric acid and o-cresol were the same in each subject.

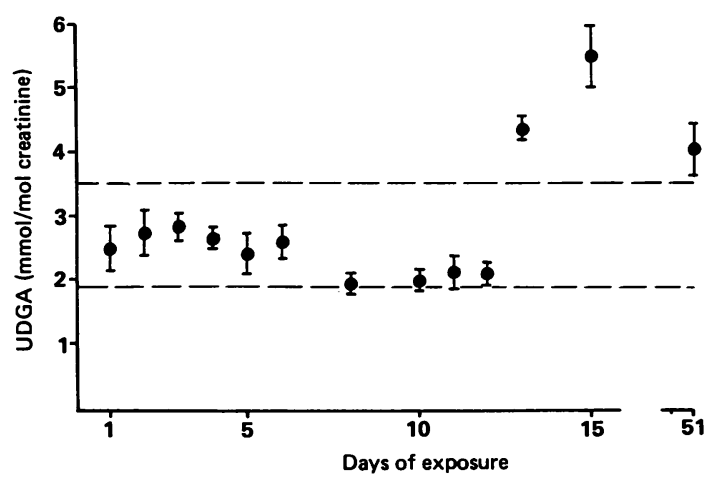

Urinary D-glucaric acid excretion (mean $\pm S E M$ ) in seven workers exposed to toluene (group B) measured after end of summer holidays. Dashed lines represent mean $\pm S D$ of total control values. Data best fitted with a third degree curve $(p<0.001, r=0.71) .19$ 
The half lives of excretion for both metabolites and postshift o-cresol/hippuric acid ratios differed among individuals (ranging from three to eight hours and from $12 \times 10^{-5}$ and $84 \times 10^{-5}$, respectively). None of these parameters, however, changed significantly after four weeks of exposure to toluene.

\section{Discussion}

High doses of toluene have been shown to increase phase I and phase II microsomal enzymes. ${ }^{3-6}$ The effect was measurable as soon as one to three days after exposure, ${ }^{45}$ was reversible within one to four days, ${ }^{4}$ and was associated with an induction of the metabolism of toluene itself. ${ }^{6}$

UDGA excretion may correlate with liver cytochrome P-450 levels, but it is possible that it represents an index of phase II drug metabolism rather than being determined by the activity of phase I enzymes. ${ }^{20}$ Furthermore, several of the enzymes in the glucoronic pathway are not localised in microsomes. It is therefore clear that an increased UDGA excretion and the induction of liver microsomal enzymes might be associated but not necessarily consequential. ${ }^{21}$

UDGA excretion, for instance, increases dramatically (up to 20 -fold) in patients chronically administered various anticonvulsant drugs and this increase was found to be related to induction of liver enzymes. ${ }^{22}$

Workers exposed to a mixture of toluene, xylene, and various pigments, but not those exposed to hexane, octane, ethyl, benzyl, and butyl alcohols, and pigments, had a twofold increase of UDGA above control levels. They also had an increased blood antipyrine half life. The authors suggested the causative role of toluene and pigments. ${ }^{23}$ Pigments were in fact able to inhibit hepatic $\mathrm{N}$-demethylase activity when administered to rats. UDGA was also studied in workers exposed to low concentrations of toluene only ${ }^{24}$ but, unlike in our study, no difference was found between exposed and control workers. It may be that the exposure of their workers was more variable than ours, and their controls included more smokers and drinkers.

It is not clear whether the observed increase of UDGA is a sign of liver enzyme induction. Certainly, UDGA increased excretion is not associated with an accelerated metabolism of toluene itself as shown by the pattern of hippuric acid and o-cresol excretions. In rats only excessively high doses of toluene induced its own metabolism ${ }^{25}$ and after experimental and occupational exposure to toluene (about $375 \mathrm{mg} / \mathrm{m}^{3}$ ) no changes in saliva antipyrine clearance were detected. $^{26}$ Taken together these data suggest that the increased UDGA excretion caused by low concentrations of toluene does not result from liver enzyme induction.

In conclusion, occupational exposure to low concentrations of toluene (below ACGIH limits) increases UDGA excretion. The increase is moderate, reversible, and not associated with induction of toluene metabolism. Owing to the high interindividual variation of UDGA excretion both in control and exposed subjects, this test is not suitable for monitoring the occupational exposures to toluene of individuals considering also that the significance of such an increase is unknown. Nevertheless, the measurement of UDGA excretion may be an index of exposure on a group basis.

We thank Professor E De Rosa and collaborators for exposure data, Professor G Mastrangelo for statistical analysis, and Ms Christina Drace-Valentini for preparing the manuscript. This work was partially supported by a grant from Consiglio Nazionale delle Ricerche.

1 Cohr KH, Stockholm J. Toluene. A toxicologic review. Scand J Work Environ Health 1979;5:71-90.

2 World Health Organisation. Toluene. Geneva: WHO, 1985. (Environmental health criteria 52.)

3 Toftgàrd R, Nilsen OG, Gustafsson JA. Dose dependent induction of rat liver microsomal cytochrome P-450 and microsomal enzymatic activities after inhalation of toluene and dichloromethane. Acta Pharmacol Toxicol 1982;51:108-14.

4 Pyykkö K. Time-course of effects of toluene on microsomal enzymes in rat liver, kidney and lung during and after inhalation exposure. Chem-Biol Interact 1983;44:299-310.

5 Pyykkö K. Age- and sex-related differences in rat liver microsomal enzymes and their inducibility by toluene. Acta Pharmacol Toxicol 1983;53:401-9.

6 Pathiratne A, Puyear RI, Brammer JD. A comparative study of the effects of benzene, toluene, and xylenes on their in vitro metabolism and drug-metabolizing enzymes in rat liver. Toxicol Appl Pharmacol 1986;82:272-80.

7 Ungváry G, Hudák A, Bors Z, Folly G. The effect of toluene on the liver assayed by quantitative morphological methods. Exp Mol Pathol 1976;25:49-59.

8 Dossing $M$. Non-invasive assessment of microsomal enzyme activity in occupational medicine: present state of knowledge and future perspectives. Int Arch Occup Environ Health 1984;53:205-18.

9 Aarts EM. Evidence for the function of D-glucaric acid as an indicator for drug induced enhanced metabolism through the glucuronic acid pathway in man. Biochem Pharmacol 1965;14:359-63.

10 Hunter J, Maxwell JD, Stewart DA, Williams R. Urinary Dglucaric excretion and total liver content of cytochrome P-450 in guinea pigs: relationship during enzyme induction and following inhibition of protein synthesis. Biochem Pharmacol 1973;22:743-7.

11 Breckenridge A. Clinical implications of enzyme induction. In: Parke AD, ed. Enzymes induction. New York, London Plenum Press, 1975:273-301.

12 National Institute for Occupational Safety and Health. Manual of analytical methods. 2nd ed. Vol 1. Cincinnati: NIOSH, 1977. (DHWE publ No 77-157-A.)

13 De Rosa E, Brugnone F, Bartolucci GB, et al. The validity of urinary metabolites as indicators of low exposures to toluene. Int Arch Occup Environ Health 1985;56:135-45.

14 Colombi A, Maroni M, Antonini C, Cassina T, Gambini A, Foà $\mathrm{V}$. Low-pH method for the enzymatic assay of D-glucaric acid in urine. Clin Chim Acta 1983;128:337-47.

15 De Rosa E, Bartolucci GB, Sigon M, Chiesura Corona $P$ Perbellini L, Brugnone F. Environmental and biological monitoring of workers exposed to low levels of toluene. Applied Industrial Hygiene 1986;1:132-7.

16 De Rosa E, Bartolucci GB, Sigon M, Callegaro R, Perbellini L Brugnone F. Hippuric acid and ortho-cresol as biologica indicators of occupational exposure to toluene. Am J Ind Med 1987;11:529-37.

17 American Conference of Governmental Industrial Hygienists. 
Threshold limit values and biological exposure indices for 19871988. Cincinnati: ACGIH, 1987.

18 Colombi A, Maroni M, Antonini C, Fait A, Zocchetti C, Foà V. Influence of sex, age, and smoking habits on the urinary excretion of D-glucaric acid. Clin Chim Acta 1983;128: 349-58.

19 Winer BJ. Statistical principles in experimental design. New York: McGraw-Hill, 1987.

20 Park BK, Breckenridge AM. Clinical implications of enzyme induction and enzyme inhibition. Clin Pharmacokinet 1981;6:1-24.

21 Okey AB, Roberts EA, Harper PA, Denison MS. Induction of drug-metabolizing enzymes: mechanisms and consequences. Clin Biochem 1986;19:132-41.

22 Hunter J, Maxwell JD, Carrella M, Steward DA, Williams R. Urinary D-glucaric acid excretion as a test for hepatic enzyme induction in man. Lancet $1971 ; \mathrm{i}: 572-5$.

23 Dolara P, Lodovici M, Buffoni F, et al. Variations of some parameters of enzyme induction in chemical workers. Ann Occup Hyg 1982;25:27-32.

24 Formenti C, Colombi A, Maroni M, Narducci M, Giampiccolo $\mathrm{R}$, Foà V. Escrezione di acido D-glucarico urinario in soggetti esposti professionalmente a basse concentrazioni di toluene. Atti del $48^{\circ}$ Congresso della Società Italiana di Medicina del Lavoro e Igiene Industriale, Pavia, Italy. Bologna: Monduzzi Editore, 1985:569-72.

25 Pyykkö K. Effects of pretreatment with toluene, phenobarbital and 3-methylcholantrene on the in vivo metabolism of toluene and on the excretion of hippuric acid in the rat. Pharmacol Res Commun 1984;16:217-25.

26 D during experimental and occupational exposure to toluene. $\mathrm{Br}$ $J$ Ind Med 1983;40:466-9.

Accepted 11 April 1989

\section{Vancouver style}

All manuscripts submitted to the $\mathrm{Br} J$ Ind Med should conform to the uniform requirements for manuscripts submitted to biomedical journals (known as the Vancouver style)

The $\mathrm{Br} J$ Ind Med, together with many other international biomedical journals, has agreed to accept articles prepared in accordance with the Vancouver style. The style (described in full in $\mathrm{Br}$ Med J, 24 February 1979, p 532) is intended to standardise requirements for authors.

References should be numbered consecutively in the order in which they are first mentioned in the text by Arabic numerals above the line on each occasion the reference is cited (Manson ${ }^{1}$ confirmed other reports ${ }^{2-5} \ldots$ ). In future references to papers submitted to the $\mathrm{Br} J$ Ind Med should include: the names of all authors if there are six or less or, if there are more, the first three followed by et al; the title of journal articles or book chapters; the titles of journals abbreviated according to the style of Index Medicus; and the first and final page numbers of the article or chapter

Examples of common forms of references are:

1 International Steering Committee of Medical Editors. Uniform requirements for manuscripts submitted to biomedical journals. Br Med J 1979;1:532-5.

2 Soter NA, Wasserman SI, Austen KF. Cold urticaria: release into the circulation of histamine and eosino-phil chemotactic factor of anaphylaxis during cold challenge. $N$ Engl J Med 1976;294:687-90.

3 Weinstein L, Swartz MN. Pathogenic properties of invading micro-organisms. In: Sodeman WA Jr, Sodeman WA, eds. Pathologic physiology: mechanisms of disease. Philadelphia: W B Saunders. 1974:457-72. 